\title{
Identification of viridans streptococci associated with bacteraemia in neutropenic cancer patients
}

\author{
D. BEIGHTON, A. D. CARR* and BERYL A. OPPENHEIM*
}

Oral Microbiology, Royal College Surgeons Department of Dental Sciences, King's College School of Medicine and Dentistry, Faculty of Clinical Dentistry, Caldecot Road, London SE5 9RW and * Department of Microbiology, Withington Hospital, West Didsbury, Manchester M20 8LR

\begin{abstract}
Summary. Twenty-three viridans streptococcal isolates from pyrexial neutropenic patients with various malignant diseases were studied in a comprehensive identification scheme. Fourteen isolates were identified as Streptococcus oralis, five as $S$. mitis and two as $S$. salivarius but the remaining two could not be identified reliably. The virulence mechanisms associated with the ability of these species to survive and grow in vivo require further investigation but may involve the production of specific glycosidase and proteolytic enzyme activities.
\end{abstract}

\section{Introduction}

Viridans streptococci were first described as causes of septicaemia in children with cancer in $1978^{1}$ and since then there have been numerous reports of such infections in neutropenic patients with malignancies. ${ }^{2-5}$ A typical clinical presentation includes shock and respiratory symptoms that may progress to the adult respiratory distress syndrome and some of these episodes have proved fatal. ${ }^{2,3,6}$ The apparent increase in the incidence of viridans streptococcal infections in compromised patients has been attributed to various factors, including the use of aggressive chemotherapeutic regimens that damage mucosal surfaces $^{2}$ and the use of selective gut decontamination, particularly with the quinolones. ${ }^{7-9}$

When viridans streptococci causing infections have been further characterised, the commercial identification kit, API-20 Strep system (bioMérieux, La Balme les Grottes, France) has often been used. This method has identified most isolates as either "Streptococcus mitis" or "S. sanguis". 2,6,7,9-11 Recently, however, there have been several significant changes in the taxonomy of the viridans streptococci; emended descriptions of $S$. sanguis, $S$. oralis, $S$. mitis, $S$. anginosus, $S$. intermedius and $S$. constellatus have been reported ${ }^{12,13}$ and new species $S$. gordonii, ${ }^{12}$ S. crista $^{14}{ }^{14} S$. vestibularis ${ }^{15}$ and $S$. parasanguis ${ }^{16}$ have been described. These taxonomic changes are not yet incorporated into commercial streptococcal identification kits. Other identification schemes have been described ${ }^{12,17}$ that incorporate many of these taxonomic changes, and this will result in the improved characterisation of medically important isolates.

We have compared results obtained with the API-20

Received 24 Aug. 1993; accepted 31 Aug. 1993.
Strep system with those obtained with a more comprehensive scheme, ${ }^{17}$ applied to a collection of viridans streptococci isolated from cases of neutropenic bacteraemia in an attempt to improve characterisation of the species responsible for this clinical picture and to obtain further understanding of the virulence mechanisms involved.

\section{Materials and methods}

\section{Source of bacteria and strain identification}

Blood cultures from pyrexial neutropenic patients treated for various malignant diseases at the Christie Hospital, Manchester, over a 3-year period were processed by either the Bactec radiometric or nonradiometric systems. Isolates were identified as viridans streptococci by standard criteria and were further characterised by the API-20 Strep system. Patient characteristics and identification of some of these strains have been described previously. ${ }^{2}$ The same strains were then identified according to the scheme of Beighton et al. ${ }^{17}$ that determines the ability of isolates to produce acid from nine carbohydrates, to hydrolyse aesculin and arginine and to hydrolyse 10 fluorogenic (4-methylumbelliferone-linked) glycosidase substrates; all tests were performed in microtitration trays. On the basis of these 21 different test results, strains of viridans streptococci may be assigned to one of the currently recognised species.

\section{Results}

Twenty-three separate isolates of viridans streptococci were available for identification by both schemes 
Table. Identification of viridans streptococcal isolates by the API-20 Strep system and the method of Beighton et al. $(1991)^{17}$

\begin{tabular}{|c|c|c|c|}
\hline \multirow{2}{*}{$\begin{array}{l}\text { Specimen } \\
\text { number }\end{array}$} & \multirow{2}{*}{$\begin{array}{l}\text { API-20 Strep } \\
\text { number }\end{array}$} & \multicolumn{2}{|c|}{ Identification by method of } \\
\hline & & API-20 Strep & Beighton et al. \\
\hline 90 F 128 & 0042401 & S. mitis & S. mitis \\
\hline B12488 & 4261441 & S. sanguis II $(57 \%)$ & $S$. oralis \\
\hline B12428 & 0270452 & S. sanguis II & S. oralis \\
\hline B 12104 & 0270441 & S. sanguis II & S. oralis \\
\hline 91 D 45 & 0260441 & S. sanguis II & S. mitis \\
\hline $91 \mathrm{D} 98$ & 0240441 & $S$. sanguis II & S. oralis \\
\hline 91 B 145 & 0040401 & S. mitis & S. oralis \\
\hline $90 \mathrm{~B} 1$ & 0040400 & S. mitis & S. oralis \\
\hline 90 B 40 & 0270461 & S. sanguis II & S. oralis \\
\hline 90 В 39 & 0240441 & S. sanguis II & S. oralis \\
\hline 90 F 107 & 0060411 & S. mitis & S. oralis \\
\hline 92 B 88 & 0260440 & S. sanguis II & S. oralis \\
\hline 92 В 89 & 0070411 & S. mitis & S. mitis \\
\hline 92 C 43 & 0070401 & $S$. mitis & S. oralis \\
\hline 92 B 8 & 0040400 & S. mitis & S. mitis \\
\hline 92 В 149 & 0040401 & S. mitis & S. oralis \\
\hline 92 A 110 & 0050401 & S. mitis & S. mitis \\
\hline 92 C 16 & 0260440 & S. sanguis II & S. oralis \\
\hline 90 E 156 & 0050401 & S. mitis & S. oralis \\
\hline 90 B 124 & 7030460 & $\begin{array}{l}\text { S. salivarius } \\
\text { (unacceptable profile) }\end{array}$ & S. salivarius \\
\hline $90 \mathrm{C} 9$ & 5070770 & $\begin{array}{l}S . \text { mutans or } \\
\text { S. salivarius } \\
\text { (low discrimination) }\end{array}$ & S. salivarius \\
\hline $90 \mathrm{D} 60$ & 4060440 & S. sanguis I $(66 \%)$ & $\dagger$ \\
\hline $91 \mathrm{D} 11$ & 7007511 & S. lactis $/ S$. diacetyl & $\dagger$ \\
\hline
\end{tabular}

$\dagger$ Identification by this scheme was not satisfactory.

(table). Each API-20 Strep system number was able to give an identification; the majority were either "S. mitis" (10) or "S. sanguis II" (9). One strain was identified as " $S$. sanguis I", one as $S$. salivarius (an unacceptable profile) another as $S$. mutans or $S$. salivarius (low discrimination) and the remaining strain was identified as $S$. lactis/S. diacetyl.

With the more recent scheme we found that the majority of strains were either $S$. oralis (14) or $S$. mitis (5). $S$. oralis was characterised by the production of sialidase, $\quad \beta$-N-acetylglucosaminidase, $\quad \beta$-N-acetylgalactosaminidase and, usually, $\beta$-galactosidase, with carbohydrate fermentation mostly limited to lactose and $\mathrm{N}$-acetylglucosamine. $\mathrm{S}$. mitis strains generally produced sialidase and often fermented melibiose, raffinose and $\mathrm{N}$-acetylglucosamine. Two strains were identified as $S$. salivarius (most tests were variable but the majority of isolates produced arabinosidase), whereas the strains identified by the API-20 Strep system as " $S$. sanguis I" and S. lactis/S. diacetyl could not be identified.

\section{Discussion}

Some confusion arises when the API-20 Strep system is used to identify viridans streptococci as it employs taxonomic nomenclature which has now been superseded. Some of this confusion arises because, for example, $S$. oralis and $S$. mitis are related but separate from $S$. sanguis strains, because they have a distinct cell-wall composition, deficient in glycerol teichoic acid and significant amounts of rhamnose but containing a ribitol teichoic acid. On the basis of these cellwall similarities, Colman and Williams ${ }^{18}$ grouped these two species into " $S$. mitior". However, genetic ${ }^{19}$ and physiological studies ${ }^{20}$ have clearly demonstrated the separate taxonomic status of these species, for which Kilian et al. ${ }^{12}$ have reported emended descriptions. The development of a new and improved version of the streptococcal identification kit by bioMérieux (Rapid ID 32 Strep system) may improve the reliability of identification but, of 17 strains of $S$. mitis, 11 required additional tests for identification and one was not identified, and of 22 strains of $S$. oralis, 14 required additional tests and one was not identified. ${ }^{21}$ With this kit, consideration should also be given to whether it can produce the correct identification of members of the "S. milleri group"- $-S$. intermedius, $S$. constellatus and $S$. anginosus - and the fact that no strains of $S$. parasanguis or $S$. crista were included in the validation exercise previously reported. ${ }^{21}$ Therefore, the identification of these strains may still present difficulties. The API-20Strep system is unsuitable for the identification of these species.

Although many different species of viridans streptococci have been described, only three $(S$. salivarius, $S$. oralis and $S$. mitis) were isolated from blood cultures from pyrexial neutropenic patients. Allowing for the different descriptions of species used in other laboratories, these results are in accord with those of others, ${ }^{1,2,6,7,9-11}$ who reported the isolation of similar species from blood cultures of patients with similar medical histories.

The reasons for the preponderance of $S$. oralis and $S$. mitis strains in this collection of isolates from pyrexial neutropenic patients is unclear. The most likely source of these strains is the oral cavity where they form a significant component of the oral flora ${ }^{22}$ and from which they may gain access to the circulatory system as a result of dental manipulations, including simple toothbrushing - which often results in transient bacteraemia, even in healthy subjects. There have been many studies of the interactions between viridans streptococci derived from the oral cavity, and salivary and serum glycoproteins that have shown that strains now identified as $S$. oralis and $S$. mitis have the greatest affinity for salivary mucin because they possess receptors for the terminal portion of sialic acid-terminating oligosaccharide side-chains. ${ }^{23}$ Similar studies have demonstrated that strains of these two species also have the greatest affinity for transferrin $;{ }^{24}$ this would appear to be mediated by the same binding mechanism as for salivary mucin.

These species also have considerable ability to degrade and utilise glycoproteins for growth. Van der Hoeven et al. ${ }^{25}$ reported that oral $S$. oralis strains exhibited the greatest ability to use salivary mucins for growth and we have reported that $S$. oralis and $S$. mitis strains are the most proteolytic of the viridans 
streptococci. ${ }^{26}$ These species, compared with representatives of all other species of viridans streptococci, display the greatest proteolytic activity when tested with various synthetic fluorogenic protease substrates, human serum transferrin and bovine serum albumin. These findings indicate that $S$. oralis and $S$. mitis are the most effective of all the viridans streptococci in obtaining nutrients from host-derived glycoproteins and this ability might explain the preponderance of these species amongst viridans streptococci isolated from neutropenic patients with septicaemia.

These data provide a further insight into the role of viridans streptococci in septicaemia that occurs in neutropenic patients and suggest that $S$. oralis and $S$. mitis are the species most likely to be isolated. To understand the virulence mechanisms of these species, more detailed information on their ability to replicate in vivo is required.

\section{References}

1. Hoecker JL, Pickering LK, Görschel D, Kohl S. Streptococcus salivarius sepsis in children with malignancies. $J$ Pediatr 1978; 92 : 337-338.

2. Burden $\mathrm{AD}$, Oppenheim BA, Crowther $\mathrm{D}$ et al. Viridans streptococcal bacteraemia in patients with haematological and solid malignancies. Eur J Cancer 1991; 27: 409-411.

3. Cohen J, Worsley AM, Goldman JM, Donnelly JP, Catovsky D, Galton DAG. Septicaemia caused by viridans streptococci in neutropenic patients with leukaemia. Lancet 1983; 2: $1452-1454$.

4. Henslee J, Bostrom B, Weisdorf D, Ramsay N, McGlave P, Kersey J. Streptococcal sepsis in bone marrow transplant patients. Lancet 1984; 1: 393

5. Pizzo PA, Ladisch S, Witebsky FG. Alpha-haemolytic streptococci: clinical significance in the cancer patient. Med Pediatr Oncol 1978; 4: 367-370.

6. McWhinney PHM, Gillespie SH, Kibbler CC, Hoffbrand AV, Prentice HG. Streptococcus mitis and ARDS in neutropenic patients. Lancet 1991; 337: 429.

7. Classen DC, Burke JP, Ford CD et al. Streptococcus mitis sepsis in bone marrow transplant patients receiving oral antimicrobial prophylaxis. Am J Med 1990; 89: 441-446.

8. Rozenberg-Arska M, Dekker AW, Verhoef J. Ciprofloxacin for selective decontamination of the alimentary tract in patients with acute leukemia during remission induction treatment: the effect on fecal flora. J Infect Dis $1985 ; 152$ : 104-107.

9. van der Lelie H, van Ketel RJ, von dem Borne AEGK, van Oers RHJ, Thomas BLM, Goudsmit R. Incidence and clinical epidemiology of streptococcal septicemia during treatment of acute myeloid leukemia. Scand J Infect Dis 1991; 23: 163-168.

10. Kern W, Linzmeier K, Kurrle E. Antimicrobial susceptibility of viridans group streptococci isolated from patients with acute leukemia receiving ofloxacin for antibacterial prophylaxis. Infection 1989; 17: 396-397.

11. Venditti M, Baiocchi P, Santini C et al. Antimicrobial susceptibilities of Streptococcus species that cause septicemia in neutropenic patients. Antimicrob Agents Chemother 1989; 33: $580-582$

12. Kilian M, Mikkelsen L, Henrichsen J. Taxonomic study of viridans streptococci; description of Streptococcus gordonii sp. nov. and emended descriptions of Streptococcus sanguis (White and Niven 1946), Streptococcus oralis (Bridge and Sneath 1982) and Streptococcus mitis (Andrewes and Horder 1906). Int J Syst Bacteriol 1989; 39: 471-484.

13. Whiley RA, Beighton D. Streptococcus constellatus sp. nov., nom. rev., Streptococcus intermedius sp. nov., nom. rev.

and emended descriptions and recognition of Streptococcus constellatus, Streptococcus intermedius and Streptococcus anginosus as distinct species. Int J Syst Bacteriol $1991 ; 41: 1-5$.

14. Handley P, Coykendall A, Beighton D, Hardie JM, Whiley RA. Streptococcus crista sp. nov., a viridans streptococcus with tufted fibrils, isolated from the human oral cavity and throat. Int J Syst Bacteriol 1991; 41 : 543-547.

15. Whiley RA, Hardie JM. Streptococcus vestibularis sp. nov. from the human oral cavity. Int J Syst Bacteriol 1988; 38: 335-339.

16. Whiley RA, Fraser HY, Douglas CWI, Hardie JM, Williams AM, Collins MD. Streptococcus parasanguis sp. nov., an atypical viridans Streptococcus from human clinical specimens. FEMS Microbiol Lett 1990; 68: 115-122.

17. Beighton D, Hardie JM, Whiley RA. A scheme for the identification of viridans streptococci. $J$ Med Microbiol 1991; 35: 367-372.

18. Colman $G$, Williams REO. Taxonomy of some human viridans streptococci. In: Wannamaker LW, Matsen JM (eds) Streptococci and streptococcal diseases. Recognition, understanding and management. New York, Academic Press Inc. 1972: 281-299.

19. Coykendall AL, Munzenmaier AJ. Deoxyribonucleic acid base sequence studies on glucan-producing and glucan-negative strains of Streptococcus mitior. Int J Syst Bacteriol 1978; 28: $511-515$.

20. Gilmour MN, Whittam TS, Kilian M, Selander RK. Genetic relationships among the oral streptococci. J Bacteriol 1987; 169: 5247-5257.

21. Freney J, Bland S, Etienne J, Desmonceaux M, Boeufgras JM, Fleurette J. Description and evaluation of the semiautomated 4-hour rapid ID 32 Strep method for identification of streptococci and members of related genera. $J$ Clin Microbiol 1992; 30: 2657-2661.

22. Frandsen EVG, Pedrazzoli V, Kilian M. Ecology of viridans streptococci in the oral cavity and pharynx. Oral Microbiol Immunol 1991; 6: 129-133.

23. Levine MJ, Tabak LA, Reddy M, Mandel ID. Nature of salivary pellicles in microbial adherence: role of salivary mucins. In: Mergenhagen SE, Rosan B (eds) Molecular basis of oral microbial adhesion. Washington DC, American Society for Microbiology. 1985: 125-130.

24. Beighton D, Whiley RA, Homer KA. Transferrin binding by Streptococcus oralis and other oral streptococci. Microbial Ecol Hlth Dis 1990; 3: 145-150.

25. van der Hoeven JS, van den Kieboom CWA, Camp PJM. Utilization of mucin by oral Streptococcus species. Antonie van Leeuwenhoek 1990: 57: 165-172.

26. Homer KA, Whiley RA, Beighton D. Proteolytic activity of oral streptococci. FEMS Microbiol Lett 1990; 67: 257-260. 